\title{
Supporting Healthful Eating Through Retail Environmental Change: Communities Putting Prevention to Work
}

\author{
Latetia V. Moore, PhD, MSPH \\ Suggested citation for this article: Moore LV. Supporting Healthful Eating Through Retail Environmental Change: \\ Communities Putting Prevention to Work. Prev Chronic Dis 2013;10:130166. DOI: \\ http://dx.doi.org/10.5888/pcd10.130166 圈.
}

More healthful eating patterns can help people achieve recommended nutrient intakes, control calorie intake, and reduce the risk of some of the leading causes of chronic illness and death in the United States such as cardiovascular disease, diabetes, and certain types of cancer (1). Making more healthful choices easily accessible may help people start and maintain more healthful eating patterns $(2,3)$. Although research and programs dedicated to improving access to more healthful food choices are under way (4), there is little empirical evidence to identify what aspects of the retail environment require intervention to improve access (5). It is unclear whether efforts should focus on improving proximity to stores, improving the selection of healthful options within stores with limited stock, making more healthful items more affordable, improving the quality of goods within stores, introducing more healthful options to an area via other retail models like farmers markets, or some combination of the above. One recent initiative that may elucidate what aspects of the environments to change to improve the diet and health of community members is Communities Putting Prevention to Work (CPPW). During the 2-year funding period beginning in 2010, 39 of the 50 CPPW communities committed to enhancing access to healthful food and evaluating the effect of this increased access on behavior (6). CPPW presented an opportunity to evaluate changes to the environment that may support people in making more healthful dietary choices.

This collection of articles in Preventing Chronic Disease presents findings from the first 7 of those 39 communities to publish results from their CPPW retail food environment initiatives. Three communities focused their efforts on improving access in corner stores. The other 4 communities chose to improve access at farmers markets in low-income areas via incentive programs or increased acceptance of food assistance benefits.

Improving access does not necessarily mean adding large, full-service grocery stores like supermarkets and supercenters to areas with low levels of access. Although these types of stores frequently offer a wider selection of highquality, affordable, and more healthful options (2), new store development may not always be possible (7). Smaller retail venues such as small grocery stores, corner stores, and fruit and vegetable markets can also play a role in ensuring communities have adequate access to more healthful foods (8).

Each of 3 highlighted CPPW initiatives working to improve access via corner stores used qualitative or quantitative baseline assessments to identify potential barriers, engage community residents, understand neighborhood context, and develop solutions to increase access. In Pitt County, North Carolina, store assessments indicated that the pricing and quality of food items in rural corner stores were similar to that of food items in urban corner stores, but the rural corner stores were more likely to carry healthful foods (9). Qualitative interview results indicated that corner store owners were willing to stock more healthful foods but perceived low customer demand for them in underserved areas, despite the fact that more than half of customers of these stores reported that a wider selection of groceries and better prices would help them buy more groceries at corner stores (10). The awardee used these findings to establish a baseline and to identify small stores that offered limited produce to target for a healthy corner store initiative. The initiative included introducing potentially profitable healthful food items, on the basis of store owner perceptions of demand and findings from customer surveys, and offering taste tests and in-store promotions to increase demand for fruits and vegetables. 
Quantitative and qualitative baseline assessments by the second of the 3 CPPW awardees in Nashville, Tennessee, focused more narrowly on 4 areas researchers identified as providing limited access, based on existing data (11). Physical assessment of the stores in these areas indicated that few of them offered fresh fruits, fresh vegetables, low-fat milk, or whole-wheat bread and none stocked items from all 4 of these food categories (11). Qualitative assessments identified a neighborhood history of poor-quality produce offered in small stores, mistrust of store proprietors, and mistrust of government (11). As in North Carolina, the Tennessee awardee used this information as a baseline and to inform the design of a corner store initiative and communications campaign. Their efforts aimed to increase awareness of the higher-quality product offerings introduced by the initiative such as seasonal fresh fruits and vegetables purchased in bulk from a local mobile market. The initiative also developed a plan to build relationships between corner store proprietors and neighborhood organizations, such as a church, to mitigate mistrust. The third CPPW grantee in Cook County, Illinois, also identified and recruited corner stores into a healthy corner store initiative and engaged community members by conducting quantitative baseline assessments and partnering with 9 community institutions including local governments, community-based organizations, and faith-based institutions (12,13). Of the 53 corner stores approached, 25 corner stores were willing to add new healthful foods to their inventory, and 21 ( $84 \%$ ) received new equipment and marketing materials and enhanced community outreach (13).

Introducing or altering inventory in corner stores is only one way of increasing access to more healthful food options. Farmers markets, farm stands, and other retail venues that sell fresh farm produce can increase access to high-quality fresh produce, be set up in a variety of locations, and be implemented at a low cost (14-16). They may also reduce the cost of healthful foods for low-income families and result in increased fruit and vegetable intake of program participants when federal food and nutrition assistance programs extend benefits to include farmers market purchases $(15,16)$. In addition to the potential positive effect on diet of farmers markets and other retail venues that sell fresh farm produce, these retail venues may also help to bolster local economies and foster business growth and tourism (14).

Each of the 4 highlighted CPPW initiatives working to improve access at farmers markets in low-income areas was able to demonstrate that increasing affordability of fruits and vegetables through a bonus incentive program is a successful strategy for increasing Supplemental Nutrition Assistance Program (SNAP) use or sales or both at farmers markets. Two CPPW initiatives were also able to demonstrate increases in fruit and vegetable consumption. In 9 farmers markets in lower-income regions of King County, Washington, SNAP/EBT (electronic benefit transfer) acceptance rates increased by $79 \%$ for market stalls after introduction of subsidized (EBT) terminals for processing SNAP cards (17). Analyses of 4 years of EBT sales data in New York City showed that by the last 2 years, markets participating in the Health Bucks program had $87 \%$ to $98 \%$ higher daily EBT sales than markets without the incentive (18). In Pennsylvania, average SNAP sales more than doubled in the first 2 years of the Philly Food Bucks program (19). Philly Food Bucks users were also more than twice as likely to report increasing fruit and vegetable consumption and trying new fruits or vegetables as non-Philly Food Bucks users. The County of San Diego Health and Human Services Agency directly attributed $48 \%$ of the $\$ 1.7$ million total market revenue in 5 farmers' markets to an incentive program that offered matched monetary incentives of up to $\$ 20$ per month (20). Participants at these markets also reported significant increases in daily consumption and weekly purchasing of fruits and vegetables and perception of overall dietary health.

Although people who live in areas with greater access to retailers of more healthful foods may have a better diet than those with limited access, dietary quality is still fairly low even in areas of high access (21). Interventions to test improving access alone versus improving access in conjunction with individual strategies that encourage people to choose more healthful foods are still needed. For these reasons, improving access to healthful foods in the community is only one of the mechanisms CPPW awardees are using to support more healthful dietary choices (6). For example, the Tennessee CPPW awardee assisted store owners with product placement to increase visibility of more healthful items and developed promotional posters, signage, and point-of-purchase flags that were posted in neighborhoods served by the stores and in the stores to increase awareness of the initiative. The awardee also provided samples of foods and beverages made with a variety of fruits and vegetables sold in the store to increase knowledge of different types of fruits and vegetables and how to prepare them.

Ensuring that all Americans have easy access to retail venues that offer affordable, healthful foods is an important step toward supporting more healthful choices and a high-quality diet in communities. Each of the 7 CPPW awardees highlighted in this commentary implemented an environmental change and has prospectively evaluated or plans to evaluate its effect. The 4 awardees improving access via farmers markets demonstrated that financial incentives increased sales at farmers markets; 2 of them also demonstrated that incentives increased fruit and vegetable intake. The 3 awardees improving access via corner stores each engaged the community to develop a context-specific approach to improving access and established a baseline. Postevaluation in each is under way. Each of the prospective program evaluations in these communities can help others understand how they can implement retail environment changes that may prompt changes in behavior. Continued evaluation efforts that prospectively evaluate retail environment changes like CPPW and stronger research study designs that can rule out alternative explanations for observed associations 
(22) can help to refine future investments in public health initiatives to improve diet and reduce the burden of nutrition-related diseases.

\section{Acknowledgments}

This research received no specific grant from any funding agency in the public, commercial, or nonprofit sectors.

\section{Author Information}

Corresponding Author: Latetia V. Moore, PhD, MSPH, Nutrition Branch, Division of Nutrition, Physical Activity, and Obesity, National Center for Chronic Disease Prevention and Health Promotion, Centers for Disease Control and Prevention, 4770 Buford Hwy NE, MS F77, Atlanta, GA 30341. Telephone: 770-488-5213. E-mail: lvmoore@cdc.gov.

\section{References}

1. Dietary Guidelines for Americans. Washington (DC): US Department of Agriculture and US Department of Health and Human Services; 2010. http://www.health.gov/dietaryguidelines/dga2010/DietaryGuidelines2010.pdf. Accessed April 9, 2013.

2. Larson NI, Story MT, Nelson MC. Neighborhood environments disparities in access to healthy foods in the US. Am J Prev Med 2009;36(1):74-81. CrossRef 囬 PubMed 国

3. Grimm K, Moore LV, Scanlon K. Access to healthier food retailers in the United States, 2011. MMWR Morb Mortal Wkly Rep. In Press.

4. Healthy Food Access Portal. PolicyLink, The Food Trust, and The Reinvestment Fund; 2013. http://www.healthyfoodaccess.org/. Accessed May 7, 2013.

5. Story M, Kaphingst KM, Robinson-O'Brien R, Glanz K. Creating healthy food and eating environments: policy and environmental approaches. Annu Rev Public Health 2008;29(1):253-72. CrossRef 因 PubMed $⿴$

6. Bunnell R, O’Neil D, Soler R, Payne R, Giles WH, Collins J, et al. Fifty communities putting prevention to work: accelerating chronic disease prevention through policy, systems and environmental change. J Community Health 2012;37(5):1081-90. CrossRef 圈 PubMed 圈

7. Access to healthier foods: opportunities and challenges for food retailers in underserved areas. Arlington (VA): Food Marketing Institute; 2011. http://www.fmi.org/docs/consumer/access-to-healthier-foods.pdf?sfvrsn=4. Accessed May 7, 2013.

8. Bodor JN, Rose D, Farley TA, Swalm C, Scott SK. Neighbourhood fruit and vegetable availability and consumption: the role of small food stores in an urban environment. Public Health Nutr 2008;11(4):413-20. CrossRef圈 PubMed 圈

9. Jilcott Pitts SB, Bringolf K, Lawton K, McGuirt J, Wall-Bassett E, Morgan J, et al. Formative evaluation for a healthy corner store initiative in Pitt County, North Carolina: assessing the rural food environment, part 1. Prev Chronic Dis 2013;10:E121. PubMed 圈

10. Jilcott Pitts SB, Bringolf K, Lloyd C, McGuirt J, Lawton K, Morgan J. Formative evaluation for a healthy corner store initiative in Pitt County, North Carolina: engaging stakeholders for a healthy corner store initiative, part 2. Prev Chronic Dis 2013;10:E120. CrossRef 圈 PubMed 圈

11. Larson C, Haushalter A, Buck T, Campbell D, Henderson T, Schlundt D. Development of a community-sensitive strategy to increase availability of fresh fruits and vegetables in Nashville's urban food deserts, 2010-2012. Prev Chronic Dis 2013;10:E125. CrossRef 国 PubMed 圈

12. Food access in Suburban Cook County. Oak Forest (IL): Cook County Department of Public Health; 2011. http://www.cookcountypublichealth.org/files/CPPW/bloc-report-031612-finallr.pdf. Accessed May 7, 2013.

13. Jaskiewicz L, Dombrowski RD, Drummond H, Barnett GM, Mason M, Welter C. Partnering with community institutions to increase access to healthful foods across municipalities. Prev Chronic Dis 2013;10:E167. CrossRef 国

14. Brown C. The impacts of local markets: a review of research on farmers markets and community supported agriculture (CSA). Am J Agric Econ 2008;90(5):1296-302. CrossRef

15. McCormack LA, Laska MN, Larson NI, Story M. Review of the nutritional impact of farmers markets and community gardens: a call for evaluation and research efforts. J Am Diet Assoc 2010;110(3):399-408. CrossRef 圈 PubMed 圂

16. Larsen K, Gilliland J. A farmers' market in a food desert: evaluating impacts on the price and availability of

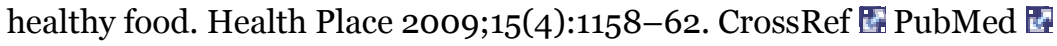


17. Cole K, McNees M, Kinney K, Fisher K, Krieger JW. Increasing access to farmers markets for beneficiaries of nutrition assistance: evaluation of the Farmers Market Access Project. Prev Chronic Dis 2013;10:E168. PubMed 国

18. Baronberg S, Dunn L, Nonas C, Dannefer R, Sacks R. The impact of New York City's Health Bucks Program on electronic benefit transfer spending at farmers markets, 2006-2009. Prev Chronic Dis 2013;10:E163.

19. Young CR, Aquilante JL, Solomon S, Colby L, Kawinzi MA, Uy N, et al. Improving fruit and vegetable consumption among low-income customers at farmers markets: Philly Food Bucks, Philadelphia, Pennsylvania, 2011. Prev Chronic Dis 2013;10:E166.

20. Lindsay S, Lambert J, Penn T, Hedges S, Ortwine K, Mei A, et al. Monetary matched incentives to encourage the purchase of fresh fruits and vegetables at farmers markets in underserved communities. Prev Chronic Dis 2013;10:E188.

21. Moore LV, Diez-Roux AV, Nettleton JA, Jacobs DR. Associations of the local food environment with diet quality a comparison of GIS and survey assessments: the Multi-Ethnic Study of Atherosclerosis. Am J Epidemiol 2008;167(8):917-24. CrossRef 国 PubMed 圈

22. Lytle LA. Measuring the food environment state of the science. Am J Prev Med 2009;36(4):S134-44. CrossRef 圈 PubMed 因

The opinions expressed by authors contributing to this journal do not necessarily reflect the opinions of the U.S. Department of Health and Human Services, the Public Health Service, the Centers for Disease Control and Prevention, or the authors' affiliated institutions.

The RIS file format is a text file containing bibliographic citations. These files are best suited for import into

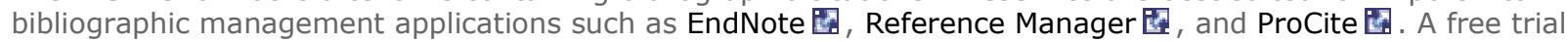
download is available at each application's web site.

For Questions About This Article Contact pcdeditor@cdc.gov

Page last reviewed: November 14, 2013

Page last updated: November 14, 2013

Content source: National Center for Chronic Disease Prevention and Health Promotion

Centers for Disease Control and Prevention 1600 Clifton Rd. Atlanta, GA 30333, USA

800-CDC-INFO (800-232-4636) TTY: (888) 232-6348 - Contact CDC-INFO

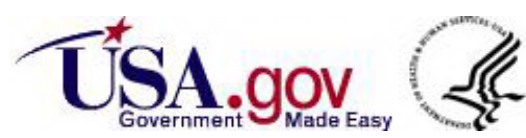

